\title{
Promoter hypermethylation may contribute to E-cadherin repression in the human salivary carcinoma ex pleomorphic adenoma
}

\author{
LIANG XIA, YUHUA HU, TING GU, LIZHEN WANG and ZHEN TIAN \\ Department of Oral Pathology, Ninth People's Hospital, \\ Shanghai Jiao Tong University School of Medicine, Shanghai 200011, P.R. China
}

Received July 7, 2017; Accepted October 13, 2017

DOI: $10.3892 /$ ijo.2017.4210

\begin{abstract}
The role of promoter methylation in the inactivation of E-cadherin $(\mathrm{CDHI})$ in salivary carcinoma ex pleomorphic adenoma (CXPA) is unknown. The objective of this study was to determine the role and potential clinical implications of $C D H 1$ promoter methylation in salivary CXPA. The $C D H 1$ promoter methylation status was determined by bisulfite sequencing PCR in 37 primary CXPA tissues and 2 CXPA cell lines. E-cadherin expression levels were determined by immunohistochemical analysis of each tumor. E-cadherin protein levels and $C D H 1$ mRNA levels were examined by immunoblotting and quantitative real-time PCR, respectively, in 2 CXPA cell lines. Cells were treated with 5-Aza-dC or TGF- $\beta 1$ to test the influence of promoter methylation on $C D H 1$ mRNA and protein expression. Associations between $\mathrm{CDH} 1$ molecular alterations and patients' clinicopathologic characteristics and prognosis were statistically evaluated. $\mathrm{CDH} 1$ promoter hypermethylation was detected in 21 of 37 tumors $(56.76 \%)$. Of these 37 tumors, 13 tumors (35.14\%) showed low E-cadherin expression. Tumors that had $\mathrm{CDH} 1$ promoter methylation had a histological tendency toward luminal differentiation $(\mathrm{P}=0.004)$, high tumor grade $(\mathrm{P}=0.005)$, high $\mathrm{T}$ stage $(\mathrm{P}=0.024)$ and high TNM stage $(\mathrm{P}=0.038)$ compared with tumors that did not. The two CXPA cell lines exhibited an inverse relationship between $C D H 1$ promoter methylation status and $C D H 1$ mRNA and protein expression. Treatment of the hypermethylated cell line with 5-Aza-dC restored $C D H 1 \mathrm{mRNA}$ and E-cadherin protein expression. The induction of hypermethylation by TGF- $\beta 1$ resulted in the repression of $C D H 1 \mathrm{mRNA}$ and protein expression. $\mathrm{CDH} 1$ is commonly silenced in CXPA through promoter
\end{abstract}

Correspondence to: Professor Zhen Tian, Department of Oral Pathology, Ninth People's Hospital, Shanghai Jiao Tong University School of Medicine, 639 Zhi-zao-ju Road, Shanghai 200011, P.R. China

E-mail: tian0304_cn@163.com

Key words: carcinoma ex pleomorphic adenoma, E-cadherin, promoter, methylation, prognosis methylation. $\mathrm{CDH} 1$ methylation is closely related to tumor cell differentiation, histological grade, lymph node metastasis and advanced TNM stage, indicating that $\mathrm{CDH} 1$ methylation may play a role in the initiation and progression of CXPA.

\section{Introduction}

E-cadherin, a 120-kDa transmembrane glycoprotein encoded by the $C D H 1$ gene located on $16 \mathrm{q} 22.1$, is a prime mediator of calcium dependent cell-cell adhesion and forms the key functional component of adherens junctions between neighboring homozygous cells (1). There is increasing evidence that modulation of this complex by different mechanisms, such as gene mutation $(2,3)$, loss of heterozygosity $(\mathrm{LOH})(4,5)$ and epigenetic and micro-RNA alternations (6-8), is an important step in the initiation and propagation of human cancers. Promoter methylation, a type of epigenetic alteration, is considered to be the predominant mechanism of $C D H 1$ inactivation. This mechanism has been recognized in many solid tumors, including salivary adenoid cystic carcinoma (ACC) (6), eyelid and oral squamous cell carcinoma (SCC) (9), gastric cancer (8), breast cancer $(7,10)$, bladder cancer (11) and colorectal adenocarcinoma $(12,13)$.

The carcinoma ex pleomorphic adenoma (CXPA) is a malignant tumor of the salivary gland that develops in or from a recurrent or long-lasting benign pleomorphic adenoma (PA). This tumor type comprises $\sim 4 \%$ of all salivary tumors and $12 \%$ of all salivary malignancies (14). Based on the data of our department, CXPA is the second most common (tied with acinic cell carcinoma) malignancy of the salivary gland in the Chinese population, accounting for $8 \%$ of all salivary malignancies (15). To date, however, the expression of E-cadherin in human salivary CXPA has been infrequently studied (16-18). Moreover, there are no reports describing the relationship between $\mathrm{CDH} 1$ promoter methylation and E-cadherin expression in salivary CXPA. Furthermore, the association between molecular changes to the $\mathrm{CDH} 1$ gene and tumor progression remains to be clarified.

In the present study, we evaluated $C D H 1$ promoter methylation status and E-cadherin expression levels in $37 \mathrm{CXPA}$ samples. We also correlated the promoter methylation status in these tumors with clinical and pathological parameters to 
determine the role of $C D H 1$ methylation in the development and progression of salivary CXPA. In addition, we analyzed the promoter methylation status as well as the messenger RNA (mRNA) and protein expression levels of $\mathrm{CDH} 1$ in $2 \mathrm{CXPA}$ cell lines: SM-AP1 and SM-AP4. To our knowledge, this is the first report of a comprehensive analysis of $\mathrm{CDH} 1$ methylation in salivary CXPA samples.

\section{Materials and methods}

Tissue samples and cell lines. Formalin-fixed and paraffinembedded tissues from 37 cases of salivary CXPA with complete clinical and pathological data were retrieved from the Department of Oral Pathology at Shanghai Ninth People's Hospital, Shanghai Jiao Tong University in Shanghai, China. Tissue sections $(4 \mu \mathrm{m})$ were stained with hematoxylin and eosin (H\&E) and were reviewed by two investigators. The tumors were histologically examined and classified as high or low grade (19). High-grade tumors exhibited $\geq 2$ of the following features: i, anaplasia with nuclear pleomorphism and prominent nucleolus; ii, frequent mitoses: $\geq 5$ per 10 highpower fields; iii, atypical mitosis; and iv, extensive coagulative tumor necrosis. The clinical stage of each patient's disease was determined according to criteria of the tumor-lymph nodemetastasis (TNM) classification system (2002) International Union Against Cancer (20). CXPAs could be classified into 2 main subtypes according to their morphological and immunohistochemical features. The classification of CXPA-L and CXPA-NL in our study followed the methods detailed by Kim et al (19). This study was approved by the ethics committee of Shanghai Jiao Tong University.

For our in vitro experiments, 2 CXPA cell lines (SM-AP1 and SM-AP4) (21) were cultured in DMEM supplemented with $100 \mathrm{U} / \mathrm{ml}$ penicillin, $100 \mathrm{mg} / \mathrm{ml}$ streptomycin, $2 \mathrm{mM}$ glutamine and $10 \%$ fetal bovine serum (FBS) and were incubated at $37^{\circ} \mathrm{C}$ in a humidified atmosphere containing $5 \% \mathrm{CO}_{2}$. Induction of $\mathrm{CDH} 1$ promoter hypermethylation in SM-AP1 cancer cells was initiated by the addition of $10 \mathrm{ng} / \mathrm{ml} \mathrm{TGF}-\beta 1$ (Peprotech, NJ, USA) to the medium for up to $72 \mathrm{~h}$. Induction of $C D H 1$ promoter demethylation in SM-AP4 cancer cells was initiated by the addition of a demethylation agent, 5-Aza-2'deoxycytidine (5-Aza-dC; Selleck, TX, USA).

DNA extraction and bisulfite-treated DNA polymerase chain reaction (BSP) amplification and direct sequencing. Genomic DNA was extracted from paraffin-embedded tumor tissues and cultured cells using the QIAamp DNA formalin-fixed paraffin-embedded (FFPE) tissue kit (Qiagen, Duesseldorf, Germany) and the QIAamp DNA Mini kit (Qiagen), respectively, according to the manufacturer's instructions. We selected regions of malignant tumor as much as possible when extracting DNA from tissue sections. Extracted DNA was treated with sodium bisulfite using the EpiTect Bisulfite kit (Qiagen) according to the manufacturer's protocol. Nested PCR primer sequences were as follows: first round, 5'-GGT AAAAGAAAAAAAAATTAGTTTG-3' and 5'-AATACCTA CAACAACAACAACAA-3'; second round, 5'-TAGAGAG GTTGGGGTTAGAG-3' and 5'-AACCCCTCCCCAAAAC RAAACTAA-3'. Methylation status was assessed at the $C D H I$ promoter region by sequencing the PCR-amplified bisulfite- treated DNA using the automated ABI PRISM 3730XL DNA sequencer (Applied Biosystems, USA), as previously described (22). The $C D H 1$ promoter region studied here contains $10 \mathrm{CpG}$ dinucleotides located in the -571- to -230-bp fragment upstream of the transcription start site. Ten random clones were selected from each sample for sequencing. Methylation status was defined as low [methylation rate $(\mathrm{MR}) \leq 20 \%$, medium $(20 \%<\mathrm{MR} \leq 40 \%)$, or high $(\mathrm{MR} \geq 40 \%)$.

Immunohistochemistry and evaluation. Immunohistochemistry (IHC) was performed on $4-\mu \mathrm{m}$ paraffin-embedded sections according to the protocol. An anti-E-cadherin receptor antibody (monoclonal mouse anti-human, dilution 1:200; Life Technologies, USA) was applied as the primary antibody for IHC detection. The IHC procedure was performed by the Envision $^{\mathrm{TM}}$ method (Dako, Glostrup, Denmark) according to the manufacturer's protocol. In the negative control samples, primary antibodies were replaced by PBS. Normal salivary gland tissue slices served as a positive control. In the CXPA samples, E-cadherin was located on the cell membrane and in the cytoplasm. Five random high-power fields were chosen from every slice to assess the E-cadherin score. The score of each slice was based on the percentage and intensity of positively stained cells. The percentage scoring system was as follows: no positive cells $(0),<50 \%$ positive tumor cells (1), $50-75 \%$ positive tumor cells (2), and $>75 \%$ positive tumor cells (3). The intensity scoring system was as follows: no staining (0), light yellow (1), yellow brown (2), and dark brown (3). The percentage score was multiplied by the intensity score and sections were divided into 2 groups based on the resulting product, as follows: low expression (score $\leq 6$ ) and high expression (score $>6$ ). IHC slides were scored by two pathologists without knowledge of the clinical data in order to eliminate bias. Discrepancies were eliminated by consensus.

Western blotting and quantitative RT-PCR (qRT-PCR). Western blotting and qRT-PCR were carried out as previously described $(23,24)$. Protein lysates were separated by $10 \%$ SDS-PAGE and electrophoretically transferred to a PVDF membrane (Millipore, MA, USA). Subsequently, the membrane was incubated with a primary monoclonal antibody followed by a fluorescent secondary antibody. $\beta$-tubulin was used as a protein loading control. Primary antibodies used for western blotting included those against E-cadherin (Abcam), vimentin (Abcam), and $\beta$-tubulin (Santa Cruz, CA, USA). Western blot bands were visualized using Imaging system (LI-COR Biosciences, Lincoln, NE, USA), and protein density was quantified using Odyssey version 1.2 software (LI-COR Biosciences). qRT-PCR was performed using SYBR-Green PCR master mix (Applied Biosystems) on an ABI 7300 system. PCR primers were as follows: CDH1 (5'-AGAACAGCAC GTACACAGCCCTAA-3' and 3'-ATCAGCAGAAGTGTCCC TGTTCCA-5') and $\beta$-actin (5'-CTCCATCCTGGCCTCGC TGT-3' and 3'-GCTGTCACCTTCACCGTTCC-5').

Statistical analysis. The data were analyzed using version 13 of the Statistical Package for Social Sciences (SPSS Inc., Chicago, IL, USA). Quantitative data were summarized using the means and standard deviations and were compared using the Student's t-test. Qualitative and ranked data were 
Table I. Correlation of E-cadherin expression with $\mathrm{CDH} 1$ methylation.

\begin{tabular}{|c|c|c|c|c|c|}
\hline \multirow[b]{2}{*}{ Group } & \multirow[b]{2}{*}{ Caterogy (n) } & \multicolumn{2}{|c|}{ Expression of E-cadherin } & \multirow[b]{2}{*}{$\chi^{2}$} & \multirow[b]{2}{*}{ P-value } \\
\hline & & Low $(\%)$ & High (\%) & & \\
\hline \multicolumn{6}{|c|}{ Methylation status } \\
\hline Low & 16 & $1 \quad(7.7)$ & $15(62.5)$ & & \\
\hline Medium & 9 & $1(7.7)$ & $8(33.3)$ & & \\
\hline High & 12 & $11(84.6)$ & $1(4.2)$ & & \\
\hline Total & 37 & 13 & 24 & 24.964 & $<0.01^{\mathrm{a}}$ \\
\hline
\end{tabular}

aStatistically significant $(\mathrm{P} \leq 0.05)$.

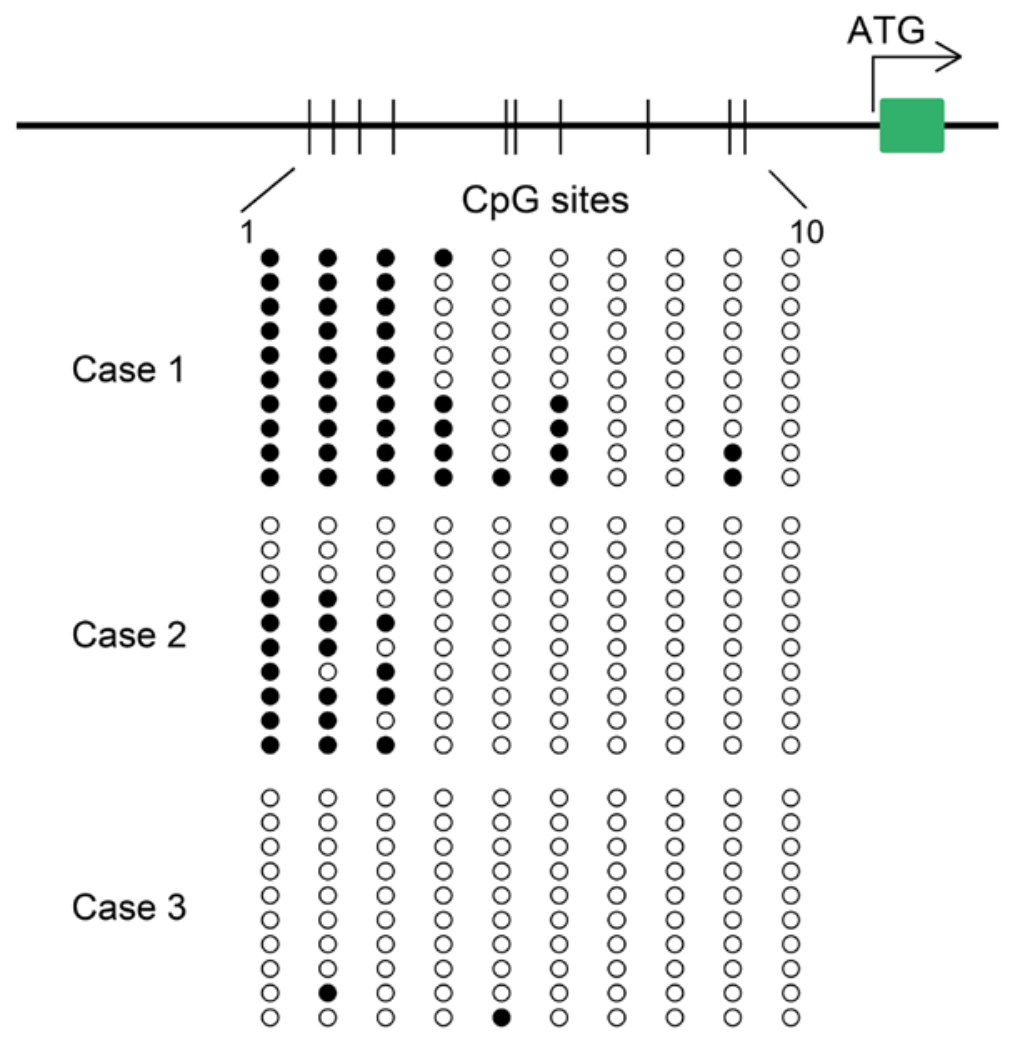

Figure 1. Case 1, case 2 and case 3 showed high, medium, and low methylation status on CDH1 promoter, with MR of 42,17 and $2 \%$ respectively.

compared using the $\chi^{2}$ test. Associations between clinicopathological variables and $C D H 1$ promoter methylation status were evaluated using Pearson's $\chi^{2}$ test. Patient survival analysis was performed by the Kaplan-Meier method, and differences were evaluated with the log-rank test. Hazard ratios (HR) and their 95\% confidence intervals (CI) were estimated using univariate and multivariate Cox proportional hazard models. All statistical analyses were considered significant when the P-value was $\leq 0.05$.

\section{Results}

Clinical and pathological characteristics. A total of 37 CXPAs from 26 males (70.27\%) and 11 females (29.73\%) were investigated in this study. The male to female ratio was 2.36 . The age range of the patients was $26-83$ years, and the mean age was
61.62 years. Twenty-nine tumors $(78.38 \%)$ originated from the major salivary glands, and 8 tumors $(21.62 \%)$ originated from the minor salivary glands. Histologically, 16 (43.24\%) tumors were classified as low grade, and 21 (56.76\%) were classified as high grade. Perineural invasion was observed in 11 of 37 patients (29.73\%). Sixteen patients (43.24\%) developed lymph node metastases. The mean follow-up time was 28.86 months. There were 17 deaths, 16 patients died of CXPA and 1 of another disease. Of those that survived, 17 patients survived without tumors and 3 survived with tumors.

Promoter methylation status of $\mathrm{CDH} 1$ and its correlation with E-cadherin expression. The methylation status of $\mathrm{CDHI}$ was analyzed in 37 salivary CXPA tissues using BSP. As shown in Table I, low, medium and high methylation of the $\mathrm{CDHI}$ promoter (Fig. 1) was found in 16 (43.24\%), 9 (24.32\%) and 


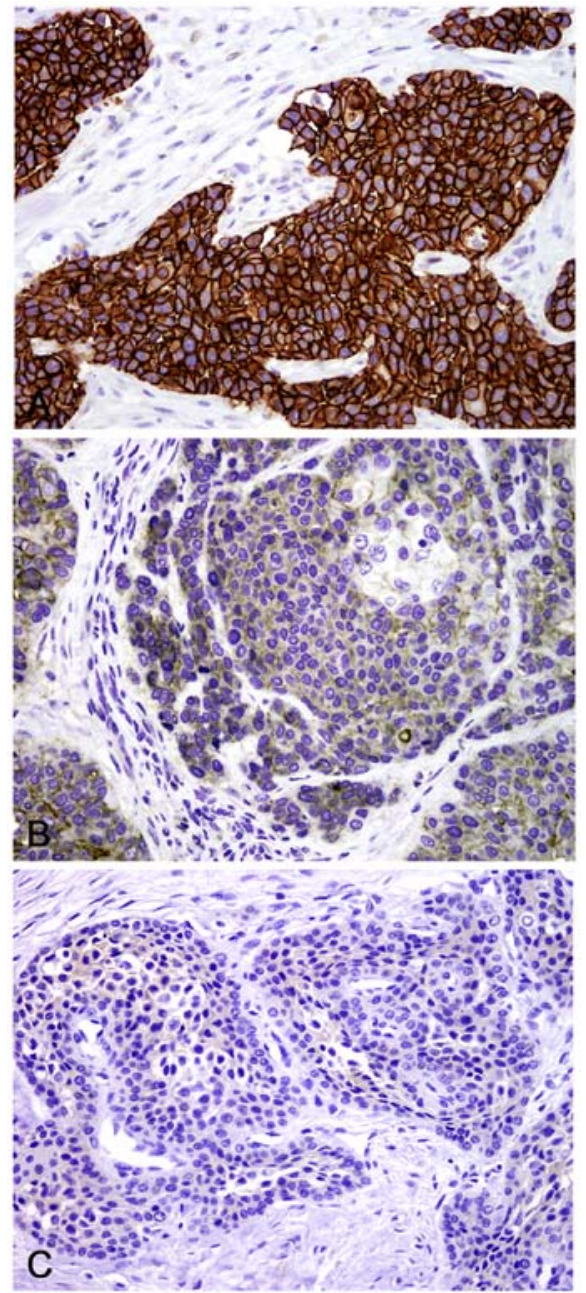

Figure 2. E-cadherin immunohistochemistry with high, low and negative expression. E-cadherin was expressed on tumor cell membrane primarily, and cytoplasm partially.
$12(32.43 \%)$ CXPA samples, respectively. IHC analysis was performed to investigate E-cadherin expression. The results showed that $13(35.14 \%)$ of 37 cases had low E-cadherin expression, while 24 (64.86\%) cases showed high E-cadherin expression (Table I and Fig. 2). As shown in Table I, we found that $\mathrm{CDH} 1$ promoter methylation was significantly lower in the high E-cadherin expression group as compared with the low E-cadherin expression group $(\mathrm{P}<0.01)$. This result indicates that the methylation status of $\mathrm{CDH} 1$ strongly correlates with E-cadherin expression.

CDH1 promoter methylation and $M R N A$ and protein expression in $C X P A$ cell lines. $C D H 1$ promoter methylation was detected in both SM-AP1 and SM-AP4 cell lines (Fig. 3A). Consistent with the notion that methylation contributes to gene inactivation, $\mathrm{CDH} 1$ hypermethylation ( $\mathrm{MR}=48 \%$ ) status resulted in lower $C D H 1 \mathrm{mRNA}$ and protein expression in SM-AP4 cell lines than $(\mathrm{MR}=23 \%)$ in SM-AP1 cell lines (Fig. 3B and C). When treated with 5-Aza-dC, a demethylating agent, SM-AP4 cells showed increased $C D H 1$ mRNA and protein expression and decreased $\mathrm{CDH} 1$ promoter methylation (Fig. 4A-C). However, SM-AP1 cells showed decreased $\mathrm{CDH} 1$ mRNA and E-cadherin expression but an elevated methylation status after TGF- $\beta 1$ treatment (Fig. 4D-F). Taken together, we suggest that promoter methylation is a predominant factor regulating $\mathrm{CDH} 1$ expression in CXPA cell lines.

Associations between CDH1 promoter methylation and clinicopathological parameters. To evaluate the clinical significance of CDH1 promoter methylation, we investigated the association between methylation status and clinicopathological features in CXPA patients. As presented in Table II, CDH1 methylation status was differentially detected according to sex, histological subtype, histological grade, and tumor
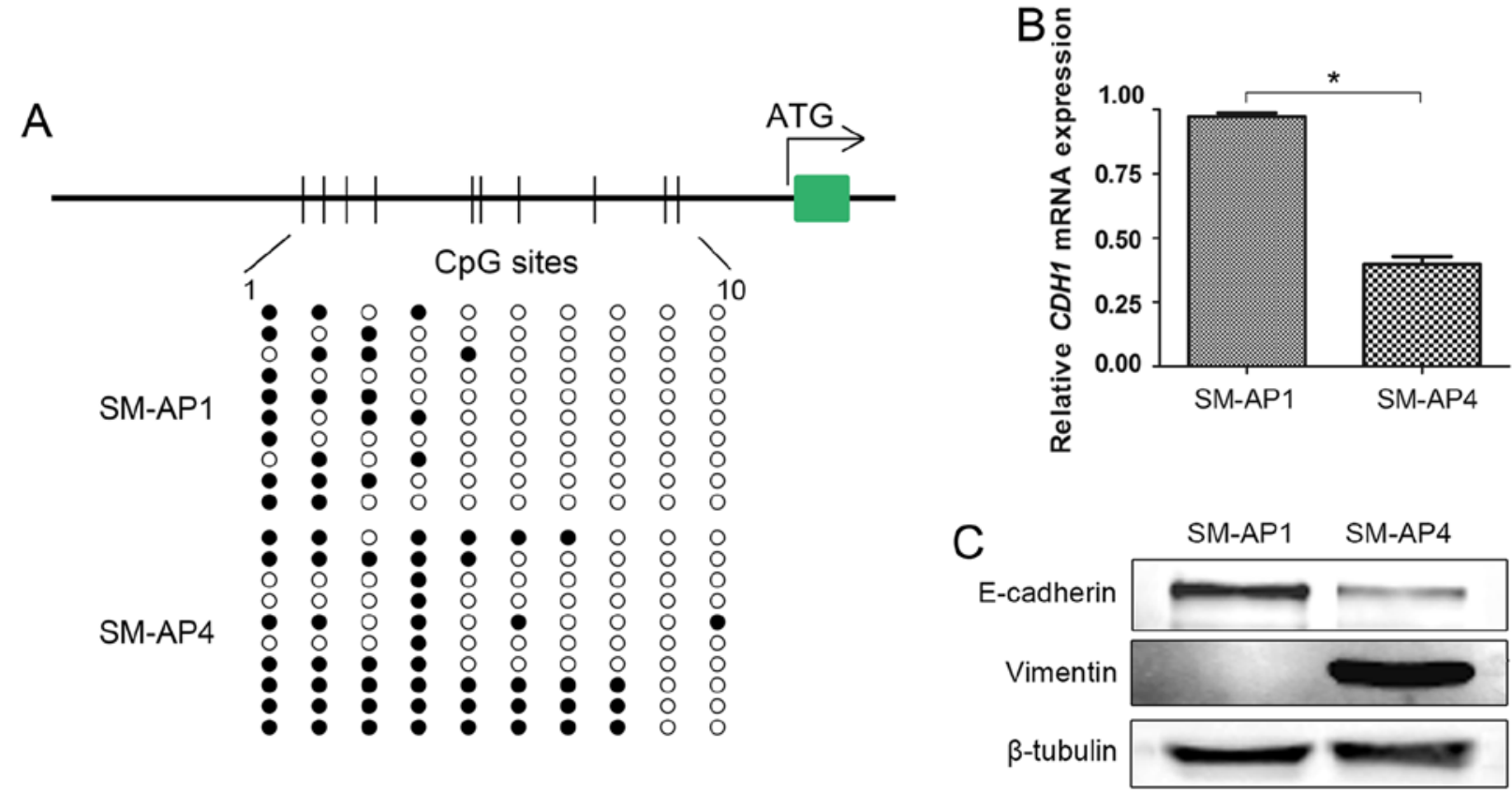

Figure 3. The methylation status and mRNA of CDH1, and E-cadherin and vimentin protein expression in SM-AP1 and SM-AP4 cell lines. (A) CDH1 promoter region methylation rate was $48 \%$ in SM-AP1 and $23 \%$ in SM-AP4. (B) The mRNA of CDH1 expression in SM-AP4 was significantly lower than that in SM-AP1 cells. 

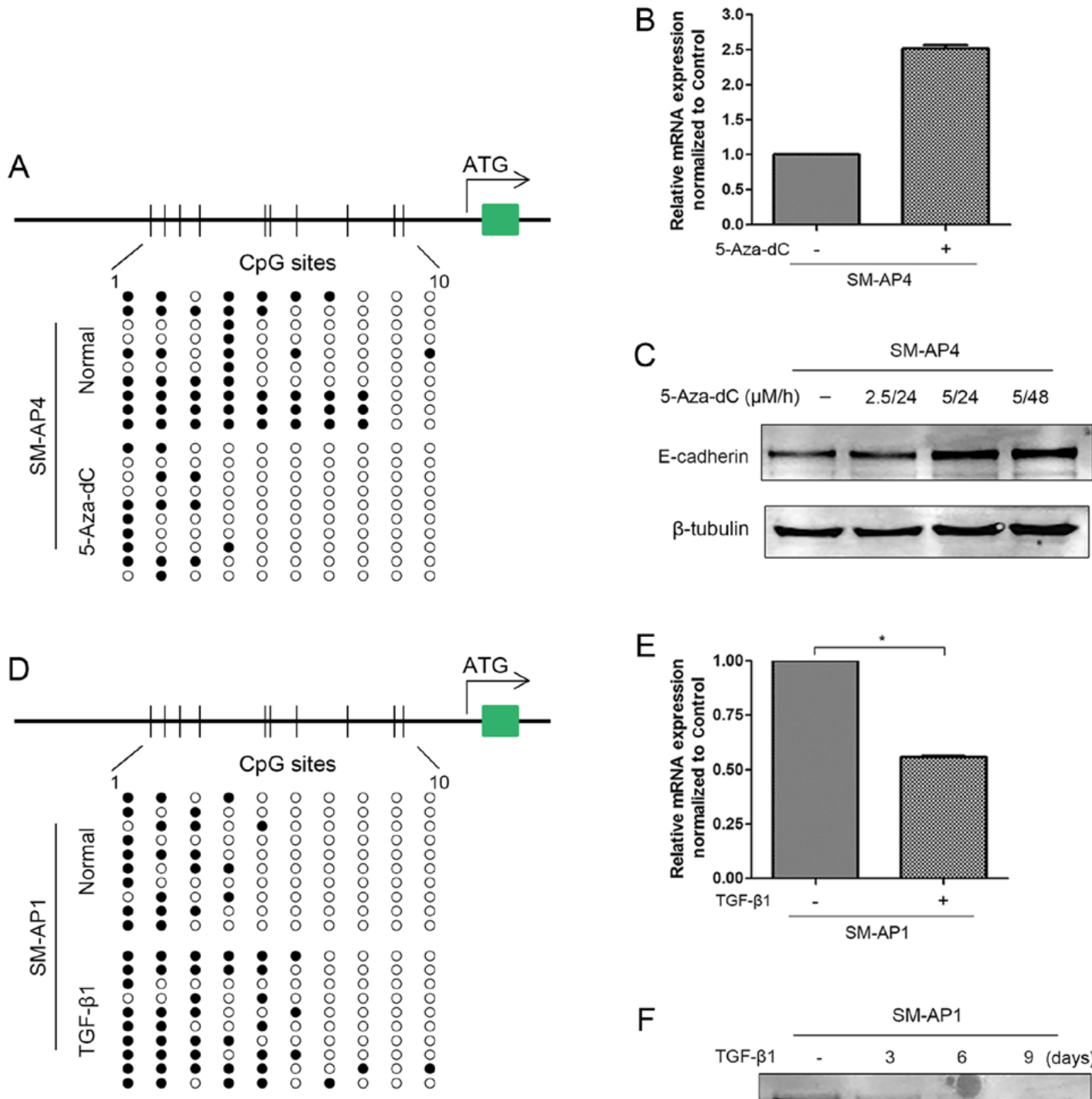

$\mathrm{E}$

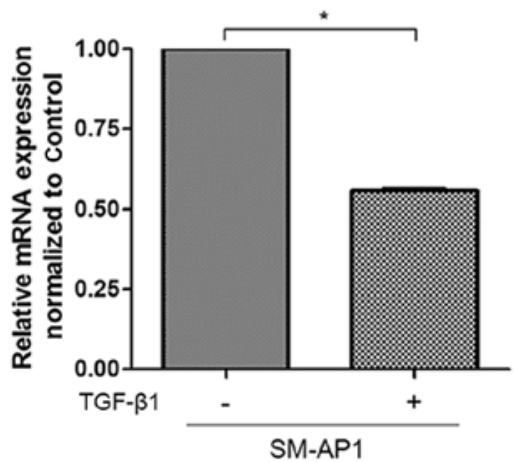

$\mathrm{F}$

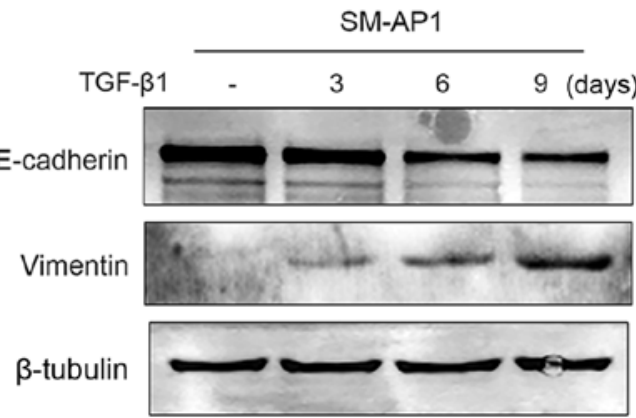

Figure 4. CDH1 promoter methylation status is associated with E-cadherin repression in 2 CXPA cell lines. (A) Schematic diagram showing the position of $10 \mathrm{CpG}$ dinucleotides at the promoter region of $\mathrm{CDH} 1$. SM-AP4 cells were treated with 5-Aza-dC $(5 \mu \mathrm{M})$ for $24 \mathrm{~h}$, and methylation of the CDH1 promoter was analyzed by bisulfite sequencing. (B) The expression of CDH1 mRNA was analyzed by quantitative real-time PCR (mean \pm SD from 3 separate experiments) after treated with 5-Aza-dC. (C) The SM-AP4 cells were treated with 5-Aza-dC for the indicated dose and time periods, and E-cadherin expression in these cells was analyzed by western blotting. (D) Schematic diagram showing the position of $10 \mathrm{CpG}$ dinucleotides at the promoter region of CDH1. SM-AP4 cells were treated with TGF- $\beta 1(5 \mathrm{ng} / \mathrm{ml})$ for 3 days, and methylation of the CDH1 promoter was analyzed by bisulfite sequencing. (E) The expression of CDH1 mRNA was analyzed by quantitative real-time PCR (mean \pm SD from 3 separate experiments) after treated with TGF- $\beta 1$. (F) The SM-AP1 cells were treated with TGF- $\beta 1(10 \mathrm{ng} / \mathrm{ml})$ for the indicated time periods, and expression of E-cadherin and vimentin in these cells was analyzed by western blotting.

$\mathrm{N}$-stage and TNM-stage. CXPA cases with high histological grade $(42.9 \%$ versus $7.1 \%, \mathrm{P}=0.005)$, lymph node metastasis (56.2\% versus $14.3 \%, \mathrm{P}=0.024)$, or advanced $\mathrm{TNM}$-stage ( $41.7 \%$ versus $7.7 \%, \mathrm{P}=0.038)$ were more likely to display high $\mathrm{CDH} 1$ promoter methylation, which indicates that promoter methylation may be a prognostic factor in CXPA. Interestingly, compared with males, females tended to present with higher $\mathrm{CDH} 1$ methylation rates $(\mathrm{P}=0.028)$. $\mathrm{CDH} 1$ methylation status was not significantly correlated with other clinicopathological parameters, such as age, tumor site or neural invasion. 
Table II. Associations between the promoter methylation status of $C D H 1$ and clinicopathological characteristics.

\begin{tabular}{|c|c|c|c|c|c|c|}
\hline \multirow[b]{2}{*}{ Characteristic } & \multirow[b]{2}{*}{ Category (no.) } & \multicolumn{3}{|c|}{ Methylation status } & \multirow[b]{2}{*}{$\chi^{2}$} & \multirow[b]{2}{*}{ P-value } \\
\hline & & Low $(\%)$ & Medium (\%) & High (\%) & & \\
\hline \multirow[t]{2}{*}{ Age (years) } & $<60(14)$ & $6(42.9)$ & $2(14.3)$ & $6(42.9)$ & \multirow[t]{2}{*}{1.688} & \multirow[t]{2}{*}{0.430} \\
\hline & $\geq 60(23)$ & $10(43.5)$ & $7(30.4)$ & $6(26.1)$ & & \\
\hline \multirow[t]{2}{*}{ Sex } & Male (26) & $13(50.0)$ & $8(30.8)$ & $5(19.2)$ & \multirow[t]{2}{*}{7.116} & \multirow[t]{2}{*}{$0.028^{\mathrm{a}}$} \\
\hline & Female (11) & $3(27.3)$ & $1(9.1)$ & $7(63.6)$ & & \\
\hline \multirow[t]{2}{*}{ Subtype } & ICXPA-L (23) & $12(52.2)$ & $8(34.8)$ & $3(13.0)$ & \multirow[t]{2}{*}{10.900} & \multirow[t]{2}{*}{$0.004^{\mathrm{a}}$} \\
\hline & ICXPA-NL (14) & $4(28.6)$ & $1(7.1)$ & $9(64.3)$ & & \\
\hline \multirow[t]{2}{*}{ Tumor site } & Major gland (29) & $12(41.4)$ & $8(27.6)$ & $9(31.0)$ & \multirow[t]{2}{*}{0.775} & \multirow[t]{2}{*}{0.679} \\
\hline & Minor gland (8) & $4(50.0)$ & $1(12.5)$ & $3(37.5)$ & & \\
\hline \multirow[t]{2}{*}{ Neural invasion } & Yes (11) & $5(42.3)$ & $4(36.4)$ & $2(18.2)$ & \multirow[t]{2}{*}{1.931} & \multirow[t]{2}{*}{0.381} \\
\hline & No (26) & $11(42.3)$ & $5(19.2)$ & $10(38.5)$ & & \\
\hline \multirow[t]{2}{*}{ Histological grade } & Low (16) & 11 (78.6) & $2(14.3)$ & $1(7.1)$ & \multirow[t]{2}{*}{10.446} & \multirow[t]{2}{*}{$0.005^{\mathrm{a}}$} \\
\hline & High (21) & $5(23.8)$ & $7(33.3)$ & $9(42.9)$ & & \\
\hline \multirow[t]{2}{*}{$\mathrm{N}$-stage } & $\mathrm{N}^{-}(21)$ & $12(57.1)$ & $6(28.6)$ & $3(14.3)$ & \multirow[t]{2}{*}{7.461} & \multirow[t]{2}{*}{$0.024^{\mathrm{a}}$} \\
\hline & $\mathrm{N}^{+}(16)$ & $4(25.0)$ & $3(18.8)$ & $9(56.2)$ & & \\
\hline \multirow[t]{2}{*}{ TNM-stage } & I+II (13) & $9(69.2)$ & $3(23.1)$ & $1 \quad(7.7)$ & \multirow[t]{2}{*}{6.520} & \multirow[t]{2}{*}{$0.038^{\mathrm{a}}$} \\
\hline & III+IV (24) & $7(29.2)$ & $7(29.2)$ & $10(41.7)$ & & \\
\hline
\end{tabular}

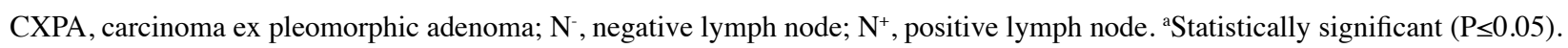

A

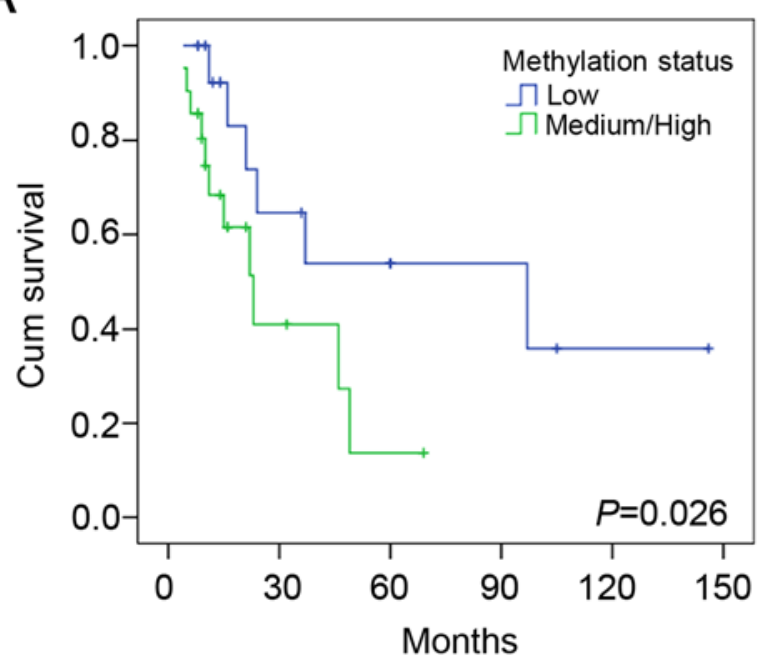

B

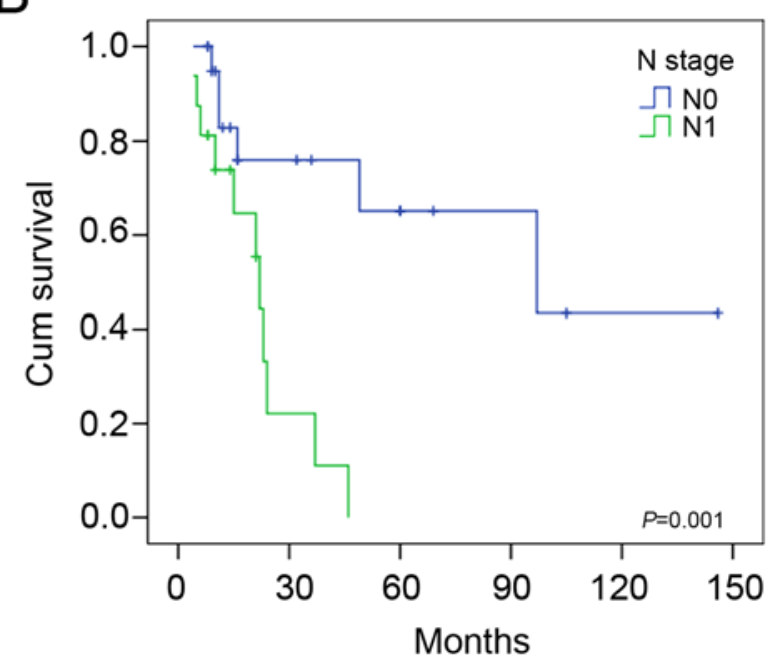

Figure 5. Kaplan-Meier survival analysis for CXPA patients, according to CDH1 methylation status and tumor N stage. (A) Compared to the CDH1 low methylation group, CXPA patients with $\mathrm{CDH} 1$ medium or high methylation status show lower overall survival $(\mathrm{P}=0.026)$. $(\mathrm{B}) \mathrm{CXPA}$ patients with lymph node metastasis show lower overall survival $(\mathrm{P}=0.001)$, compared to those without lymph node metastasis.

Survival analysis. Survival curves were generated for all 37 salivary CXPA cases. Methylation of the CDH1 promoter was significantly associated with overall survival (log-rank test, $\mathrm{P}=0.026$ ) (Fig. 5). In univariate analyses, lymph node metastasis $(\mathrm{P}=0.004)$ and $\mathrm{CDH} 1$ promoter hypermethylation $(\mathrm{P}=0.030)$ were significantly associated with poor overall survival (Table III). To determine whether the association between $\mathrm{CDH} 1$ promoter methylation and survival was independent of other parameters, a multivariate analysis was performed including $\mathrm{N}$-stage and $\mathrm{CDH} 1$ promoter methylation as co-factors. The multivariate analysis showed that lymph node metastasis $(\mathrm{P}=0.010)$ is independently associated with overall survival (Table III) and is an independent prognostic factor in CXPA. 
Table III. Summary of Cox proportional hazard models for the overall survival of salivary CXPAs.

\begin{tabular}{|c|c|c|c|c|}
\hline \multirow[b]{2}{*}{ Characteristic } & \multirow[b]{2}{*}{ Hazard ratio } & \multicolumn{2}{|c|}{ Hazard ratio $(95 \% \mathrm{CI})$} & \multirow[b]{2}{*}{ P-value } \\
\hline & & Lower & Upper & \\
\hline \multicolumn{5}{|l|}{ Univariate } \\
\hline Age $<60$ vs. $\geq 60$ & 3.011 & 0.976 & 9.296 & 0.055 \\
\hline Sex, male vs. female & 1.116 & 0.411 & 3.032 & 0.830 \\
\hline Subtype CXPA-L vs. CXPA-NL & 0.394 & 0.136 & 1.143 & 0.087 \\
\hline Location major vs. minor & 1.260 & 0.407 & 3.903 & 0.689 \\
\hline Neural invasion positive vs. negative & 1.738 & 0.634 & 4.764 & 0.283 \\
\hline Grade low vs. high & 34.266 & 0.329 & 71.975 & 0.136 \\
\hline T-stage T1/T2 vs. T3/T4 & 1.063 & 0.402 & 2.812 & 0.901 \\
\hline N-stage $\mathrm{N}^{-}$vs. $\mathrm{N}^{+}$ & 5.573 & 1.727 & 17.982 & $0.004^{\mathrm{a}}$ \\
\hline TMN-stage I/II vs. III/IV & 3.043 & 0.862 & 10.743 & 0.084 \\
\hline E-cadherin low vs. high & 1.380 & 0.478 & 3.989 & 0.552 \\
\hline Methylation low vs. medium/high & 2.761 & 0.945 & 8.061 & $0.030^{\mathrm{a}}$ \\
\hline \multicolumn{5}{|l|}{ Multivariate } \\
\hline $\mathrm{N}$-stage $\mathrm{N}^{-}$vs. $\mathrm{N}^{+}$ & 4.739 & 1.446 & 15.528 & $0.010^{\mathrm{a}}$ \\
\hline Methylation low vs. medium/high & 2.043 & 0.680 & 6.137 & $0.053^{\mathrm{a}}$ \\
\hline
\end{tabular}

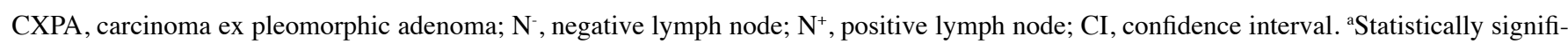
cant $(\mathrm{P} \leq 0.05)$.

\section{Discussion}

Generally, alterations in gene expression are mainly achieved by genetic and epigenetic methods. Genetic alternations primarily change the structure or number of a certain gene, whereas epigenetic alternations occur at the transcriptional level (9). CpG island methylation in the promoter region is a common epigenetic method of modifying gene expression. $\mathrm{CpG}$ methylation has been shown to modulate tumor progression in various cancer types, including esophageal squamous cell carcinoma $(25,26)$, oral squamous cell carcinoma (27), salivary CXPA (28) and ACC (29). This modulation occurs mainly via the inactivation of tumor suppressor genes such as p16, MGMT, DAPK and RASSFIA. Altered $C D H 1$ promoter methylation status has been shown to be the key factor in E-cadherin silencing in many tumors $(7,9,11)$. $C D H 1$ silencing is directly related to advanced tumor stage and an aggressive phenotype (7). This is the first study to evaluate $\mathrm{CDH} 1$ promoter methylation status in salivary CXPA. In this study, we have also demonstrated the relationship between E-cadherin expression and $\mathrm{CDH} 1$ promoter methylation.

In our study, an absence of E-cadherin expression was found in $35.14 \%$ (13/37) of CXPA cases. This is similar to a study by Zhang et al (6), which reported a negative E-cadherin detection rate of $38.33 \%$ across 60 ACC cases. However, negative E-cadherin expression was found in $68.42 \%(26 / 38)$ of eyelid SCC cases and $87.26 \%(18 / 23)$ of oral SCC cases. A study (7) in breast cancer showed a $42.33 \%(58 / 137)$ rate of reduced E-cadherin expression. It seems that E-cadherin reduction occurs with varying frequencies in different tumor types and at a relatively low frequency in salivary gland tumors specifically. In the meantime, we detected $C D H 1$ promoter methylation using the BSP method, which is considered the 'gold standard' for determining DNA methylation and has the advantage of detecting methylation at each $\mathrm{CpG}$ site individually. Our study indicated that the $C D H 1$ methylation rate in CXPA was $67.57 \%(25 / 37)$. This rate is similar to that of many other tumors, including primary lung cancer (88\%) (30), breast carcinoma $(65-95 \%)(7,10,31,32)$ and colorectal carcinoma (52\%) (33). We found that DNA methylation preferentially occurred in the first four $\mathrm{CpG}$ islands compared with the other CpG islands.

We then analyzed the association between $\mathrm{CDH} 1$ methylation status and E-cadherin expression in CXPA patients. This analysis demonstrated that $C D H 1$ methylation was significantly correlated with decreased E-cadherin expression $(\mathrm{P}<0.001)$ in clinical specimens. In addition, we evaluated the $\mathrm{CDH} 1$ methylation status and the corresponding $\mathrm{CDH} 1 \mathrm{mRNA}$ and protein levels in SM-AP1 and SM-AP4 cell lines. Consistent with the above results, cells with higher $\mathrm{CDH1}$ methylation levels showed lower E-cadherin expression. Furthermore, to demonstrate that methylation is the critical factor in the silencing of E-cadherin expression, a dynamic experiment was performed in vitro. The demethylating agent 5 -Aza-dC restored $\mathrm{CDHI}$ mRNA and protein expression levels by reversing the high methylation status of SM-AP4 cell lines. Conversely, upregulation of $C D H 1$ methylation levels via TGF- $\beta 1$ treatment resulted in a repression of $C D H 1$ mRNA and protein levels in SM-AP1 cells. TGF- $\beta 1$-induced $C D H 1$ promoter methylation was achieved by inducing the expression of the Snail protein, a transcriptional factor that binds the $\mathrm{CDH} 1$ promoter region and recruits DNA methyltransferases (DNMT), which 
subsequently methylate the DNA fragment (34). TGF- $\beta 1$ is a signaling molecule that mediates the epithelial-mesenchymal transition (EMT) (34). The hallmark of EMT is the loss of E-cadherin expression. In in vitro experiments, TGF- $\beta 1$ treatment of SM-AP1 cells resulted in the downregulation of the epithelial marker E-cadherin and upregulation of the mesenchymal marker vimentin. This indicated that the EMT process might play a role in the repression of E-cadherin in salivary CXPA.

Despite these results, however, $\mathrm{CDH} 1$ promoter methylation was not associated with the downregulation of E-cadherin expression levels in each case. As shown in Table I, E-cadherin expression was absent in one sample in the low-methylation group. Various studies have demonstrated that $\mathrm{CDH} 1$ expression could be repressed by mechanisms other than promoter methylation, such as changes in chromatin structure, $\mathrm{LOH}$ at 16q22.1, inactivating gene mutations, specific transcriptional factors, and translational and post-translational regulation $(5,8,35)$. Thus, taken together, we suggest that E-cadherin expression levels are primarily, but not solely, regulated by DNA methylation in CXPA both in vivo and in vitro. Other regulatory mechanisms affecting $\mathrm{CDH} 1$ in $\mathrm{CXPA}$ may be investigated in further studies.

Consistent with similar studies in eyelid SCC (9), colorectal cancer (13) and breast cancer (32), the association of $C D H 1$ methylation with cervical lymph node metastasis, histological grade and advanced tumor stage suggests that the CDHl gene may be particularly important in salivary CXPA tumor progression. Consequently, CDH1 methylation, as well as $\mathrm{N}$ stage, is a strong predicator of overall survival in patients with CXPA in univariate survival analyses. However, in multivariate survival analyses, lymph node metastasis was shown to be an independent prognostic factor of overall survival for CXPA patients. Our findings provide evidence of the potential usefulness of $\mathrm{CDH} 1$ methylation status as an informative prognostic biomarker in patients with CXPA.

Reduction in E-cadherin expression is reportedly correlated with invasion, metastasis and recurrence of tumors in patients with oral squamous cell (36), bladder (37), and breast carcinomas (32). However, we observed no association between E-cadherin expression and any of the clinicopathological parameters that were investigated in the present study (data not shown). This discrepancy may be due to the smaller sample size of our study.

In conclusion, the present study indicates that DNA promoter methylation is the most common molecular abnormality of the $C D H 1$ gene in salivary CXPA. Moreover, $\mathrm{CDH} 1$ promoter methylation is associated with histological differentiation, histological grade, tumor N stage and TNM stage. Methylation status may play a significant role in CXPA carcinogenesis and tumor progression and may be a reliable prognostic biomarker of poor patient survival. Further study of the correlation between abnormalities in the $\mathrm{CDHI}$ gene and protein expression as well as interactions with other genes in salivary CXPA is therefore warranted.

\section{Acknowledgements}

This study was supported by the Chinese Nature Science Foundation (grant nos. 81272976 and 81372910).

\section{References}

1. Wijnhoven BP, Dinjens WN and Pignatelli M: E-cadherincatenin cell-cell adhesion complex and human cancer. Br J Surg 87: 992-1005, 2000

2. Corso G, Intra M, Trentin C, Veronesi P and Galimberti V: $\mathrm{CDH} 1$ germline mutations and hereditary lobular breast cancer. Fam Cancer 15: 215-219, 2016.

3. Corso G, Figueiredo J, Biffi R, Trentin C, Bonanni B, Feroce I, Serrano D, Cassano E, Annibale B, Melo S, et al: E-cadherin germline mutation carriers: Clinical management and genetic implications. Cancer Metastasis Rev 33: 1081-1094, 2014.

4. Carter BS, Ewing CM, Ward WS, Treiger BF, Aalders TW, Schalken JA, Epstein JI and Isaacs WB: Allelic loss of chromosomes 16q and 10q in human prostate cancer. Proc Natl Acad Sci USA 87: 8751-8755, 1990.

5. Sato T, Tanigami A, Yamakawa K, Akiyama F, Kasumi F, Sakamoto G and Nakamura Y: Allelotype of breast cancer: Cumulative allele losses promote tumor progression in primary breast cancer. Cancer Res 50: 7184-7189, 1990.

6. Zhang CY, Mao L, Li L, Tian Z, Zhou XJ, Zhang ZY and Li J: Promoter methylation as a common mechanism for inactivating E-cadherin in human salivary gland adenoid cystic carcinoma. Cancer 110: 87-95, 2007.

7. Shargh SA, Sakizli M, Khalaj V, Movafagh A, Yazdi H, Hagigatjou E, Sayad A, Mansouri N, Mortazavi-Tabatabaei SA and Khorram Khorshid HR: Downregulation of E-cadherin expression in breast cancer by promoter hypermethylation and its relation with progression and prognosis of tumor. Med Oncol 31: 250, 2014.

8. Cui H, Wang L, Gong P, Zhao C, Zhang S, Zhang K, Zhou R, Zhao Z and Fan H: Deregulation between miR-29b/c and DNMT3A is associated with epigenetic silencing of the CDH1 gene, affecting cell migration and invasion in gastric cancer. PLoS One 10: e0123926, 2015.

9. Wang YQ, Yuan Y, Jiang S and Jiang H: Promoter methylation and expression of $\mathrm{CDH} 1$ and susceptibility and prognosis of eyelid squamous cell carcinoma. Tumour Biol 37: 9521-9526, 2016.

10. Lombaerts $M$, van Wezel T, Philippo K, Dierssen JW, Zimmerman RM, Oosting J, van Eijk R, Eilers PH, van de Water B, Cornelisse CJ, et al: E-cadherin transcriptional downregulation by promoter methylation but not mutation is related to epithelial-to-mesenchymal transition in breast cancer cell lines. Br J Cancer 94: 661-671, 2006.

11. Li G, Liu Y, Yin H, Zhang X, Mo X, Tang J and Chen W: E-cadherin gene promoter hypermethylation may contribute to the risk of bladder cancer among Asian populations. Gene 534: 48-53, 2014.

12. Michailidi C, Theocharis S, Tsourouflis G, Pletsa V, Kouraklis G, Patsouris E, Papavassiliou AG and Troungos C: Expression and promoter methylation status of hMLH1, MGMT, APC, and $\mathrm{CDH} 1$ genes in patients with colon adenocarcinoma. Exp Biol Med (Maywood) 240: 1599-1605, 2015.

13. Kim SA, Inamura K, Yamauchi M, Nishihara R, Mima K, Sukawa Y, Li T, Yasunari M, Morikawa T, Fitzgerald KC, et al: Loss of CDH1 (E-cadherin) expression is associated with infiltrative tumour growth and lymph node metastasis. Br J Cancer 114: 199-206, 2016.

14. Gnepp D, Brandwein-Gensler M, El-Naggar A and Nagao T: Carcinoma ex pleomorphic adenoma. In: World Health Organization Classification of Tumours: Pathology and Genetics of Head and Neck Tumours. Barnes L, Eveson JW, Reichart P and Sidransky D (eds). IARC Press, Lyon, pp242-243, 2005.

15. Tian Z, Li L, Wang L, Hu Y and Li J: Salivary gland neoplasms in oral and maxillofacial regions: A 23-year retrospective study of 6982 cases in an eastern Chinese population. Int J Oral Maxillofac Surg 39: 235-242, 2010.

16. Prabhu S, Kaveri H and Rekha K: Benign, malignant salivary gland tumors: Comparison of immunohistochemical expression of e-cadherin. Oral Oncol 45: 594-599, 2009.

17. Economopoulou P, Hanby A and Odell EW: Expression of E-cadherin, cellular differentiation and polarity in epithelial salivary neoplasms. Oral Oncol 36: 515-518, 2000.

18. Xin W and Paulino AF: Prognostic factors in malignant mixed tumors of the salivary gland: Correlation of immunohistochemical markers with histologic classification. Ann Diagn Pathol 6: 205-210, 2002.

19. Kim JW, Kwon GY, Roh JL, Choi SH, Nam SY, Kim SY and Cho KJ: Carcinoma ex pleomorphic adenoma of the salivary glands: Distinct clinicopathologic features and immunoprofiles between subgroups according to cellular differentiation. J Korean Med Sci 26: 1277-1285, 2011. 
20. Sobin LHWC: TNM Classification of Malignant Tumors. 6th edition. John Wiley \& Sons, Inc., New York, NY, 2002.

21. Maruyama S, Cheng J, Shingaki S, Tamura T, Asakawa S, Minoshima S, Shimizu Y, Shimizu N and Saku T: Establishment and characterization of pleomorphic adenoma cell systems: An in-vitro demonstration of carcinomas arising secondarily from adenomas in the salivary gland. BMC Cancer 9: 247, 2009.

22. Rotondo JC, Selvatici R, Di Domenico M, Marci R, Vesce F, Tognon M and Martini F: Methylation loss at H19 imprinted gene correlates with methylenetetrahydrofolate reductase gene promoter hypermethylation in semen samples from infertile males. Epigenetics 8: 990-997, 2013.

23. Liu H, Xu J, Zhou L, Yun X, Chen L, Wang S, Sun L, Wen Y and $\mathrm{Gu} \mathrm{J}$ : Hepatitis B virus large surface antigen promotes liver carcinogenesis by activating the Src/PI3K/Akt pathway. Cancer Res 71: 7547-7557, 2011.

24. Zhang YQ, Wei XL, Liang YK, Chen WL, Zhang F, Bai JW, Qiu SQ, Du CW, Huang WH and Zhang GJ: Over-expressed Twist associates with markers of epithelial mesenchymal transition and predicts poor prognosis in breast cancers via ERK and Akt activation. PLoS One 10: e0135851, 2015.

25. Guo W, Cui L, Wang C, Guo Y, Shen S, Kuang G and Dong Z: Decreased expression of RASSF1A and up-regulation of RASSF1C is associated with esophageal squamous cell carcinoma. Clin Exp Metastasis 31: 521-533, 2014.

26. Bai J, Zhang X, Hu K, Liu B, Wang H, Li A, Lin F, Zhang L, Sun X, Du Z, et al: Silencing DNA methyltransferase 1 (DNMT1) inhibits proliferation, metastasis and invasion in ESCC by suppressing methylation of RASSF1A and DAPK. Oncotarget 7: 44129-44141, 2016.

27. Pannone G, Santoro A, Feola A, Bufo P, Papagerakis P, Lo Muzio L, Staibano S, Ionna F, Longo F, Franco R, et al: The role of E-cadherin down-regulation in oral cancer: $\mathrm{CDH} 1$ gene expression and epigenetic blockage. Curr Cancer Drug Targets 14: $115-127,2014$.

28. Hu YH, Zhang CY, Tian Z, Wang LZ and Li J: Aberrant protein expression and promoter methylation of p16 gene are correlated with malignant transformation of salivary pleomorphic adenoma. Arch Pathol Lab Med 135: 882-889, 2011.
29. Li J,El-Naggar A and Mao L: Promoter methylation of p16INK4a, RASSF1A, and DAPK is frequent in salivary adenoid cystic carcinoma. Cancer 104: 771-776, 2005.

30. Yan F, Shen N, Pang J, Molina JR, Yang P and Liu S: The DNA methyltransferase DNMT1 and tyrosine-protein kinase KIT cooperatively promote resistance to 5-Aza-2'-deoxycytidine (Decitabine) and Midostaurin (PKC412) in lung cancer cells. J Biol Chem 290: 18480-18494, 2015.

31. Nass SJ, Herman JG, Gabrielson E, Iversen PW, Parl FF, Davidson NE and Graff JR: Aberrant methylation of the estrogen receptor and E-cadherin 5' $\mathrm{CpG}$ islands increases with malignant progression in human breast cancer. Cancer Res 60: 4346-4348, 2000.

32. Liu J, Sun X, Qin S, Wang H, Du N, Li Y, Pang Y, Wang C, $\mathrm{Xu} \mathrm{C}$ and Ren $\mathrm{H}$ : CDH1 promoter methylation correlates with decreased gene expression and poor prognosis in patients with breast cancer. Oncol Lett 11: 2635-2643, 2016.

33. Li YX, Lu Y, Li CY, Yuan P and Lin SS: Role of CDH1 promoter methylation in colorectal carcinogenesis: A meta-analysis. DNA Cell Biol 33: 455-462, 2014.

34. Dong C, Wu Y, Yao J, Wang Y, Yu Y, Rychahou PG, Evers BM and Zhou BP: G9a interacts with Snail and is critical for Snailmediated E-cadherin repression in human breast cancer. J Clin Invest 122: 1469-1486, 2012.

35. Dong C, Wu Y, Wang Y, Wang C, Kang T, Rychahou PG, Chi YI, Evers BM and Zhou BP: Interaction with Suv39H1 is critical for Snail-mediated E-cadherin repression in breast cancer. Oncogene 32: 1351-1362, 2013

36. Nakayama S, Sasaki A, Mese H, Alcalde RE, Tsuji T and Matsumura T: The E-cadherin gene is silenced by CpG methylation in human oral squamous cell carcinomas. Int $\mathrm{J}$ Cancer 93: 667-673, 2001.

37. Kashibuchi K, Tomita K, Schalken JA, Kume H, Takeuchi T and Kitamura T: The prognostic value of E-cadherin, alpha-, betaand gamma-catenin in bladder cancer patients who underwent radical cystectomy. Int J Urol 14: 789-794, 2007. 